\title{
Sport participation Constraints of Malaysian University Students
}

\begin{abstract}
The purpose of this paper is to examine the reasons that keep Malaysian university students from participating in sport activities during their leisure time. The three-dimensional leisure constraints model was used as the theoretical framework for the study. The sample consisted of 303 students from University Putra Malaysia using survey instruments based on Crawford and Godbey's (1987) Leisure Constraints Model. The instrument is designed to measure three types of constraints to sport participation: (1) structural, (2) interpersonal and (3) intrapersonal. Data were analyzed by descriptive statistics, t-tests and ANOVA. The results suggest the subjects were constrained most by structural factors such as lack of information about existing sport activities and facilities, inconvenient facility location and inconvenient facility operating hours. Female students experienced higher levels of structural and intrapersonal constraints than their male counterparts. Implications of the findings for sport administrators were given to overcome some constraints, and increase student's participation in sport activities.
\end{abstract}

Keyword: Leisure Constraint Model, Sport Participation Constraints, Physical Activity 